\title{
Uma análise das evidências de validade brasileiras do PMK
}

\author{
Fermino Fernandes Sisto ${ }^{1}$ - Universidade São Francisco, Itatiba, Brasil
}

\begin{abstract}
Resumo
Tendo em vista a proposta e a quantidade de medidas provenientes do PMK, foram colocados como objeto de análise os estudos de evidência de validade fornecidos pelo Manual. De fato, o interesse é buscar os fundamentos da interpretabilidade dos resultados de um instrumento com uma pretensão dessa magnitude. Como resultado, encontrou-se que as análises fatoriais realizadas não fornecem subsídios para a estrutura proposta para a interpretação das distintas medidas do PMK. Ao lado disso, os estudos com grupo-critério apresentados é, quando muito, incipiente e não fornece evidências de interpretabilidade para quase nenhum dos denominados seis fatores. As evidências apresentadas são confusas, há incoerências entre correlação e análise de variância e a interpretabilidade do teste não fica demonstrada pelas pesquisas.
\end{abstract}

Palavras-chave: PMK, Evidência de validade, Interpretabilidade.

\section{An analysis of the evidences of Brazilian validities about the PMK}

\begin{abstract}
Considering the proposal and amount of measures concerning with the PMK, the analysis of the studies of evidence of validity supplied by the Manual were placed under investigation. In fact, the interest is to search for foundations of the interpretability of the results of a test with a pretentiousness of this magnitude. As a result, the factorial analyzes do not support the proposed structure for the interpretation of the different measures of the PMK. Besides, the presented studies with criterion group were as much as incipient and do not furnish evidences of interpretability for almost none of the named six factors. The showed evidences are confusing, there are incoherencies between the concept of correlation and variance analysis and the interpretability of the test is not demonstrated by the researches.

Keywords: PMK, Evidences of validity, Interpretability.
\end{abstract}

Um dos testes psicológicos mais utilizados, no Brasil, talvez seja o PMK: Psicodiagnóstico Miocinético (Mira, 2004), pois para exames de seleção e de peritagem para o trânsito ele tem estado presente desde algumas décadas. Tem sido divulgado como sua grande vantagem a não-treinabilidade, dificultando que as pessoas aprendam respostas esperadas nos concursos e avaliações. A esse respeito, hoje no Brasil é bastante comum encontrar na internet as respostas para uma grande parte dos testes brasileiros, como também pessoas que se dispõem a ensinar como responder a diversos instrumentos de avaliação psicológica.

Além dessa vantagem, ele é um teste bastante antigo. De fato, o PMK: Psicodiagnóstico Miocinético foi oficialmente apresentado por Mira y Lopes em 1939, na Academia Real de Medicina de Londres, setor de Psiquiatria. Para a construção de seu teste, preferiu a forma que, no Manual, foi denominada de teste expressivo. Por teste expressivo entendia-se que a avaliação deveria ocorrer sobre a produção da pessoa, em contraposição à percepção e interpretação de um

\footnotetext{
${ }^{1}$ E-mail: fermino.sisto@saofrancisco.edu.br
}

estímulo em particular; ao lado disso, não seria utilizada a linguagem oral como forma de expressão do entrevistado. Um exemplo desse tipo de teste, na época, era o desenho da figura de um homem. Em decorrência, construiu uma prova dependente dos músculos e seus movimentos e, segundo se explicitou no Manual (Mira, 2004), com possibilidade de interpretação psicológica por meio de sua fundamentação na teoria Motriz da Consciência.

No Manual também é informada a correspondência entre o tônus muscular dinâmico e o tônus emocional e ativo. Apresenta como conclusão que, ao se realizar o PMK sem o controle visual, avaliase o tônus postural e atitudinal involuntário. A informação assim obtida seria interpretada como o nível de energia vital da pessoa, propulsora da ação individual.

Por sua vez, com base no princípio da dissociação miocinética foram afirmadas as diferenças entre os dois hemisférios cerebrais. No mesmo Manual, é defendido que um hemisfério não seria apenas um "complemento do outro", mas teriam também distintas especialidades e se manifestariam por distintos canais. Dessa forma, ao mesmo tempo em que manteriam sua individualidade, conservariam também uma comunalidade e suas inter-relações. 
Nesse contexto, haveria uma parte dominante e que seria a mais evoluída e mais influenciada pelas circunstâncias sociais, culturais e educacionais. A forma de observar ou obter essas informações dar-seia por meio das manifestações da mão direita, para os destros, e da esquerda, para os sinistros. Paralelamente, a parte dominada seria a menos desenvolvida e inconsciente da pessoa e, em razão disso, não estaria sendo influenciada social e culturalmente, nem pela educação. Sua manifestação seria pela mão direita para os sinistros e a esquerda para os destros, e esses dados se refeririam a aspectos constitucionais, pois seriam genotípicos, endógenos, inconscientes e forneceriam informações sobre o temperamento (Myra, 2004). Nesse contexto, estaria menos influenciada pelo ambiente no qual a pessoa se criou e interage.

São propostas 38 medidas para cada uma das mãos, com vistas a analisar os aspectos constitucionais e inconscientes da personalidade (mão sinistra) e os conscientes e mais situacionais (mão destra), totalizando 76 medidas. Os estímulos usados são os lineogramas (horizontal, sagital e vertical), os ziguezagues, as escadas e círculos, as cadeias (sagitais e verticais), as paralelas egocífugas e Us verticais, e as paralelas egocípetas e Us sagitais. Todas essas medidas foram consideradas necessárias para se avaliar a personalidade das pessoas e seriam obtidas por meio de repetição de traçados previamente determinados, em posições distintas e sem a visão de sua produção, a não ser no seu início.

Os dados quantitativos das medidas do PMK forneceriam informações também sobre o tônus vital (elação ou depressão), agressividade (auto ou heteroagressividade), reação vivencial (extratensão ou intratensão), emotividade (escassa ou hiperemotividade), dimensão tensional (excitabilidade ou inibição) e predomínio tensional (impulsividade ou rigidez). No Manual, esses aspectos avaliados foram denominados de fatores, sem qualquer indicação ou explicitação das razões para usar um termo tão específico da psicometria. Para avaliar esses seis fatores, os diferentes estímulos são combinados entre si, mas a decisão não é tomada por uma soma deles, pois cada um é avaliado separadamente, possui um gráfico individual e a avaliação se dá por tendência a ultrapassar um ponto de corte. Também, e agora de forma global, propõe oferecer diagnóstico em relação ao que, no Manual (capítulo 10, denominado Características Típicas do PMK dentro das Grandes Constelações da Personalidade), é chamado de grandes constelações da personalidade (normais, limítrofes e patológicas). Apesar da importância dessa possibilidade diagnóstica, ela não será detalhada, mas comentada em "Discussão". Essa decisão se deve ao fato de que as diferenciações entre esses três grupos não estão muito claramente definidas em termos de sintomas, ficando difícil a interpretação de seus limites e seus significados.

Acrescente-se a isso que é descrita e comentada uma grande quantidade de quadros, psicopatológicos, próximos a, e de outras naturezas, para os quais o PMK forneceria indicações com base na combinação e interpretação de seus resultados (capítulo 11, Característica do PMK em Neurologia). $\mathrm{Na}$ realidade eles são derivados das três possibilidades de interpretação propostas pelo Manual, sendo uma delas informar sobre os aspectos de personalidade mais constitucionais e os mais circunstanciais (mãos destra e sinistra), a outra os seis fatores e, finalmente, a terceira concernente às três grandes constelações da personalidade. Indicar todos os quadros descritos tomaria muito espaço. No entanto, a título de ilustração das possibilidades diagnósticas descritas, acrescentar-se-á que o PMK também oferece formas para interpretar problemas, desde intoxicações pelos mais diferentes produtos (nicotina, alcaloides, analgésicos e manganês, por exemplo) até doenças infecciosas, traumatismos cranianos, doenças neurológicas (hereditárias, congênitas e/ou degenerativas), síndrome de Klinefelter, trissomia do cromossomo X, como também níveis de inteligência.

Tendo em vista toda essa proposta e a quantidade de medidas provenientes do PMK, foram colocados como objeto de análise os estudos de evidência de validade fornecidos pelo Manual. De fato, o interesse é buscar os fundamentos da interpretabilidade dos resultados de um instrumento com uma pretensão dessa magnitude.

É também necessário considerar a dificuldade de se recuperar as publicações elencadas no Manual. Em razão disso, optou-se por trabalhar com as informações fornecidas, valendo-se do suposto que a autora do Manual tenha selecionado as consideradas relevantes e necessárias de cada estudo com vistas a uma consistente e precisa fundamentação do PMK. Ao mesmo tempo, que a autora selecionou as possibilidades interpretativas do PMK com base nas pesquisas já realizadas e que evidenciaram suas validades para diagnóstico.

\section{Sobre as evidências de validade do PMK}

O Manual dedica todo o capítulo 12 (dez páginas) ao tema "Validade e Fidedignidade do PMK". Apresenta estudos desde 1940.

Dentre outras informações oferecidas, aparentemente em 1949, no Brasil, é fornecida a "padronização definitiva do PMK" (p. 191). Outra informação interessante, na página 190, é que é 
afirmado que as correlações do PMK com outros testes de personalidade são quase sempre baixas e se justificam esses resultados com base no fato de que eles foram construídos fundamentados em teorias muito distintas da do PMK. Nesse sentido, as informações seriam diferentes e cada teste mediria aspectos diferenciados da personalidade.

Até abrir o primeiro subitem desse capítulo, são citados muitos estudos. Sobre agressividade, informa-se que há aproximadamente 40, mas não são fornecidos resultados de nenhum deles. Neste estudo não serão retratadas todas as investigações que são citadas em continuidade. Foram selecionadas as que dizem respeito à análise aqui propostas, e procurou-se configurar como são os dados e as informações principais que o Manual oferece quanto às possibilidades de interpretação do teste, ou seja, suas evidências de validade.

Nesse contexto, em uma pesquisa de 1940, Mira y López estudou 110 doentes mentais com diagnóstico psiquiátrico, na expectativa de que, em grupos claramente diferenciados, as características seriam mais "exageradas e indiscutíveis" (p. 190). Justificou-se que não foram apresentadas as correlações no Manual, porque as medidas dos lineogramas eram diferentes das de hoje. Ao lado disso, as conclusões proporcionadas não informam sobre as diferenças encontradas em razão dos 10 grupos com patologias distintas.

Mira y López, Mira e Pereira (1949) tiveram como grupos de estudos os homicidas, índios e adultos normais. Foi relatado que a média ponderada indicou que os adultos normais foram os menos agressivos, seguidos dos índios, e os homicidas forneceram os maiores indicadores de agressividade. Nessa mesma direção, Kussrow e Lares (1950) pesquisaram adolescentes normais, masculinos, escolhidos ao acaso em uma escola de curso "secundário", conforme denominação da época. Tendo por base as informações obtidas pelos traçados das mãos direita e esquerda, elas foram correlacionadas; segundo o Manual "estudaram 13 correlações pelo método do scatter diagram, com a fórmula de Pearson". Concluíram que alguns traçados são "mais representativos" da agressividade.

É citado o estudo de Bessa e Scwarzstein (1951) sobre a validade do PMK em pessoas normais, cujo processo estaria baseado no que foi denominado de processo de juízes competentes. Cada um dos 12 juízes, funcionários de uma mesma instituição, forneceu uma nota, considerando o "comportamento concreto e habitual de cada um deles" (p. 192), posto que eles foram, simultaneamente, juízes e sujeitos da pesquisa. Foram relatadas correlações que variaram de
0,61 a 0,79 e esses dados foram considerados evidências de validade para as medidas de emotividade, agressividade e elação. Nesse estudo foram consideradas as medidas das mãos direita e esquerda, mas não foram apresentadas as correlações em relação a cada uma delas.

Os dados desse trabalho sofreram mais análises (Bessa, 1952), fornecendo coeficientes de correlação entre todos os traçados do PMK e os dados dos juízes referentes à emotividade, agressividade e elação, acrescidos da intratensão. Foram apresentados 38 coeficientes de correlação de 1,05 (p. 193) a 0,51 (os coeficientes deveriam variar de -1 a 1 ), dos quais 17 se referem à mão direita, nove à mão esquerda, 11 a ambas as mãos e um não é especificado. A respeito desse estudo, o Manual considera as "direções metodológicas altamente consistentes" (p. 193).

Takala (1953) publicou um estudo denominado Studies of psychomotor personality tests que aparentemente deve ser o mesmo que é citado no Manual como Analysis of the Mira Test (p. 193), pois ambos parecem ter 63 páginas e são do mesmo ano. Fornece correlações entre as medidas relacionadas à mão direita e à sinistra. $\mathrm{O}$ Manual relata 34 coeficientes, 17 para cada mão. A interpretação apresentada no Manual foi que as variáveis (subtestes) "revelaram uma correlação bastante elevada no conjunto" (p. 194).

Cita também que o autor não encontrou diferenças significativas entre a mão direita e esquerda. Ao lado disso, foi comentado que a análise fatorial resultou em três fatores e justificou-se que esse resultado é consistente, pois as "personalidades coerentes, tanto nas bem estruturadas como em personalidades patológicas" tenderiam a apresentar correlações altas (não houve nenhuma); "as correlações baixas, nos casos fortemente incoerentes, e correlações medianas nos outros casos" (p. 194).

Preocupado com outros aspectos do PMK, Talmadge (1958) investigou se os movimentos gráficos motores são precisos e internamente consistentes e qual sua relação com temperamento, pela escala de Thurstone. Concluiu que os movimentos gráficos motores são estáveis, com uma precisão de 0,62. No entanto, as relações entre os temperamentos e as medidas do PMK forneceram correlações muito baixas.

É informado com algum detalhe o estudo de Rennes (1965), no qual investigou o PMK por meio de uma análise fatorial com 200 pessoas do sexo masculino, supostamente normais. Foram extraídos 10 fatores pelo método centróide de Thurstone, mas para realizar a rotação varimax foram retiradas 10 variáveis, ficando com 80. A combinação produzida pelos 10 
fatores, segundo se depreende, produziu medidas muito diferentes das preconizadas pelo Manual, possibilitando que fossem somadas medidas de diferentes figuras, inclusive das diferentes mãos. No Manual é interpretado que "As conclusões são bastante confusas e negativas, pois não concordam com o sistema interpretativo de Mira y Lopez...” (p. 196).

Finalmente, o Manual oferece "alguns índices de correlação que, de forma mais eficiente, podem ajudar os usuários do teste na interpretação da sua validade" (p. 198). É informado que esses dados são provenientes de oito fontes e estão mostrados no Quadro 12.3 (p. 199). Ao lado disso, é informado que se trabalhará com o valor de 0,50 como aceitável, apesar de antes haver afirmado que o valor de 0,71 seria suficiente para que a validade da medida fosse satisfatória.

Nesse Quadro 12.3 há seis colunas. A primeira se refere às fontes, referidas por número, mas sem legenda. A segunda é denominada Variáveis, a terceira refere-se às Amostras (adolescentes e adultos), a quarta ao Número de Casos (com variação de 11 a 382), a quinta informa as Correlações e, finalmente, a relacionada ao Método (validade simultânea, split half method, reteste, validade concorrente, "com correção de atenuação").

Essas são as informações básicas do Manual a respeito dos estudos de evidências de validade, ou seja, daqueles que possibilitariam a interpretação psicológica dos resultados. De certa forma, ao ser colocado dessa maneira, possibilita a interpretação de que esses resultados seriam necessários e suficientes para sustentar a interpretabilidade de todas as informações fornecidas pelo PMK e comentadas anteriormente. No item seguinte serão discutidos esses dados e seus significados.

\section{Discussão}

Antes de discutir os resultados sobre as evidências de validade apresentadas, serão feitas algumas considerações a respeito de informações veiculadas ao longo do Manual. $\mathrm{Na}$ realidade, essas informações, somadas às considerações sobre os resultados de pesquisa sobre o PMK, podem fornecer um quadro de bastante dúvida e implicações quanto ao significado da interpretabilidade possível desse teste.

No Manual é informado que o interesse de Mira y Lopez por provas usando as técnicas expressivas se deveu a que, na época da construção do PMK, veiculava-se que com esse tipo de procedimento as pessoas não se projetavam, em oposição à psicanálise e aos testes projetivos, mas reagiam como podiam e independentemente da vontade. Mais precisamente "Nos testes expressivos, os indivíduos não se projetam em lugar algum, concentram-se, pelo contrário, em sim mesmos, reagindo como podem, com seu controle habitual e com inteira independência de sua vontade." (Mira, 2004, p. 21). No entanto, já eram bastante conhecidos, na época, testes expressivos nos quais se defendia que as pessoas se projetavam e já havia critérios para análise. A esse respeito, Campos (1999) defendeu que, historicamente, pode-se considerar que o trabalho de Ricci, realizado em 1887, na Bolonha, foi a primeira investigação sobre o desenho que pode ser considerado como um teste e fenômeno expressivos. Também Goodenough, em 1926, já fornecia critérios para avaliação de traços de personalidade pelo desenho da figura de um homem. É interessante destacar que esses trabalhos eram bastante conhecidos nos centros de pesquisa de então e foram, e continuam sendo, citados nos estudos mais sérios da área.

Quanto à afirmação de que as correlações do PMK com outros testes de personalidade são quase sempre baixas porque eles são construídos com fundamentos em teorias distintas, a autora deixa claras duas perspectivas. Por um lado, que não vale a pena buscar evidência de validade entre testes de personalidade com fundamentos teóricos diferentes, pois os coeficientes de correlação seriam sempre baixos ou nulos, o que as pesquisas têm mostrado não ser verdade (Anastasi, 1988; Arias, 1996). Por outro lado, que as formas possíveis de evidências de validade para o PMK estariam relacionadas à estrutura interna dos itens (análise fatorial, funcionamento diferencial dos itens, processo de resposta, por exemplo) e a grupos-critério (Arias, 1996).

No entanto, e caso seja aceita a argumentação da autora, observa-se no Manual que as análises fatoriais realizadas não fornecem subsídios para a estrutura proposta para a interpretação das distintas medidas do PMK. Ao lado disso, os estudos com grupo-critério apresentados são, quando muito, incipientes e não fornecem evidências de interpretabilidade para quase nenhuma evidência dos denominados seis fatores (tônus vital, agressividade, reação vivencial, emotividade, dimensão tensional e predomínio tensional). A esse respeito, deve-se considerar que, na realidade, podem ser doze, pois eles supostamente medem um contínuo de dois aspectos da personalidade e não há qualquer demonstração de que este seja realmente um contínuo do ponto de vista psicológico e empírico. De fato, pode-se aceitar que eles poderiam formar um contínuo comportamental, com base em alguma teoria, mas que eles realmente o meçam é um dado que não aparece nos estudos empíricos realizados. 
É necessário considerar, igualmente, que há uma predileção por estudo de correlação que, como é sabido, não fornece informações sobre diferenças de grupo, que seria o caso de diagnósticos diferenciais, como também de grupos-critério (Guilford, 1936; Nunnally, 1967; Nunnally, 1972; Cronbach, 1983; Anastasi, 1988; Aiken, 1997). Nesse contexto, não se sabe exatamente qual o sentido que se pode dar aos resultados relatados no Manual.

Quanto à avaliação das grandes constelações da personalidade (normais, limítrofes e patológicas) e de quadros psicopatológicos derivados, não se fornecem indicações suficientes que permitam concluir que aquela informação se refere a uma patologia em particular. Em outros termos, não há evidências com grupos-critério que indiquem que aquela informação discrimine uma patologia de outra ou outras. Menos ainda no que se refere aos quadros que resultariam da combinação dessas constelações, dos aspectos de personalidade mais constitucionais e dos mais circunstanciais (mãos destra e sinistra) e dos seis fatores, conforme comentado no início deste estudo.

O PMK também informa que é possível interpretar problemas neurológicos, desde intoxicações pelos mais diferentes produtos até doenças infecciosas, traumatismos cranianos, doenças neurológicas, como também níveis de inteligência. Não obstante, não são oferecidas evidências de validade que justifiquem qualquer interpretação nesse sentido.

Quando se lê que há 40 estudos sobre agressividade, mas não são fornecidos os resultados, a questão que fica no ar é para que serve essa informação em termos de interpretabilidade dos dados? Com qual objetivo se colocou essa informação? Se não se mostram os resultados, como saber se diferenciou ou não os grupos e o que diferenciou? Como replicar esses estudos?

Seria possível pensar que por ser um teste bastante antigo, poder-se-ia esperar uma quantidade de estudos bastante grande, pois deveria estar minimamente provocando o interesse em realizar estudos acadêmicos a seu respeito. Novamente não é isso que se observa na literatura nacional. Uma busca nas revistas nacionais ou pelos bancos de teses e dissertações nacionais não produziu uma dezena de trabalhos nos últimos 20 anos. Na década anterior há uns poucos estudos, a maior parte deles apresentados no Simpósio 50 Anos do PMK, mas com pouquíssima informação sobre estudos de validade. O que se pode perguntar é por que os pesquisadores não se interessam por investigar e publicar pesquisas sobre o PMK? Poder-se-ia pensar que a causa seria pela dificuldade em aplicação e avaliação. Nada obstante, há que se lembrar que a literatura nacional possui uma grande quantidade de publicações sobre o teste de Rorschach, cujas dificuldades em relação à aplicação e correção são notoriamente conhecidas.

Com referência ao Prólogo à Terceira Edição (Mira, 2004, p. 15), no qual a autora afirma que a Vetor Editora passou a ser responsável "pela realização de novas pesquisas com o teste, algumas das quais já estão publicadas e outras planejadas e em pleno desenvolvimento", não foi possível comprovar quais foram essas pesquisas já publicadas, nem se observaram publicações posteriores nos meios normais de divulgação de pesquisas, isto é, as revistas. É bom lembrar que durante alguns anos a Vetor Editora manteve a publicação de uma revista de psicologia.

Nessa mesma edição, há uma página denominada $\mathrm{O}$ Editor, na qual é informado um software para correção. Diz que mais de quatro mil softwares foram distribuídos gratuitamente. Ao lado disso, como já havia muitas tabelas novas e mudanças na sequência de aplicação, resolveram publicar uma nova edição. Há que se considerar, também, que o preço de compra dele é alto, conforme uma tentativa fracassada de compra feita no ano de 2009. Nesse texto não se faz menção a qualquer estudo de validade que justificaria uma nova edição; fica clara a não-preocupação com a interpretabilidade do teste ou das normas do teste.

Ao lado disso, e diferentemente do que se poderia esperar, ele é pouco ensinado nas faculdades de psicologia brasileiras. É sabido que muitas faculdades possuem o material necessário, mas ele não está entre os instrumentos de avaliação psicológica tratado em disciplinas acadêmicas. Qual seria a razão para os professores de psicologia não terem interesse nem em pesquisar nem em ensinar o PMK, se ele é tão usado? Em contraposição, o teste de Rorschach e outros testes de personalidade, não tão complicados quanto à aplicação e avaliação, continuam sendo ensinados.

Voltando aos dados mais especificamente apresentados no capítulo concernente à validade $\mathrm{e}$ precisão, algumas considerações necessitam ser feitas. Elas são apresentadas praticamente seguindo a mesma ordem de apresentação do item anterior.

Em relação à pesquisa de Mira y López (1940), justificou-se que não foram apresentadas as correlações, porque as medidas dos lineogramas eram diferentes das de hoje. Não obstante, afirmam que houve diferenças entre as mãos direita e esquerda e que elas indicariam o grau de coesão da personalidade. A pergunta que se pode colocar ante as informações oferecidas é, se os dados não servem para uma finalidade, como eles podem servir para outra? Devese considerar, ainda, que há uma contradição nessa indicação da análise dos dados realizada, pois se a 
intenção era observar diferenças, a correlação não seria uma boa opção de análise para subsidiar a conclusão que buscavam. Mais ainda, afirma-se que houve diferenças entre as mãos direita e esquerda e que elas indicariam o grau de coesão da personalidade, o que se consubstanciaria em uma conclusão difícil de entender diante do tratamento estatístico usado (Guilford, 1936; Nunnally, 1967; Anastasi, 1988; Arias, 1996; Aiken, 1997).

O estudo de Kussrow e Lares (1950) com adolescentes normais, masculinos, escolhidos ao acaso em relação de uma escola de curso "secundário", no qual concluíram que alguns traçados são "mais representativos" da agressividade, também deixa muitas dúvidas e questões. Ao se analisarem as informações oferecidas é difícil saber como chegaram a essa conclusão, pois não havia grupo caracterizado como mais agressivo, e o correlacionar as pontuações das várias medidas não seria o procedimento mais adequado para discriminar a melhor ou as melhores medidas de agressividade. A presença de grupos extremos, um bastante caracterizado quanto a ser agressivo e outro como não-agressivo, dificilmente seria questionada como necessária para se inferir uma conclusão como a apresentada (Nunnally, 1967; Nunnally, 1972; Cronbach, 1983; Anastasi, 1988; Aiken, 1997).

A respeito do estudo de Bessa (1952), apesar de o Manual considerar as "direções metodológicas altamente consistentes" (p. 193), talvez o número de pessoas envolvidas nesse estudo favorecesse a colocação de uma série de questionamentos quanto a considerar esse resultado como tão promissor. Deve-se salientar que não se tratava de um grupo de pessoas minoritário por algum critério, mas sim de pessoas normais. Dessa forma, é bastante razoável supor que a possibilidade de haver representantes de pessoas com tendências acentuadas (tanto em alta intensidade quanto em baixa) em qualquer uma das medidas (emotividade, agressividade, elação e intratensão) seria bastante baixa. De fato, foi uma classificação de pessoas cujo intervalo de variação deve ter sido muito pequeno e sem pessoas que representassem toda a extensão a ser medida pelo teste. Em razão disso, para se diferenciarem traços de personalidade entre as pessoas não seria necessário que todos os traços possuíssem pessoas que representassem nitidamente os diferentes traços? Se não há grupos de pessoas caracterizados por diferentes traços, o que estaria sendo diferenciado? E com 12 pessoas?

É interessante salientar algo mais. No estudo de Bessa e Scwarzstein (1951) e Bessa (1952) sobre a validade do PMK em pessoas normais, por meio de "juízes competentes" as correlações foram altas e os resultados foram exaltados. Seria a opinião de colegas mais importante que instrumentos psicológicos validados, mesmo que estejam fundamentados em teorias diferentes? Cada um dos juízes teve a mesma teoria de personalidade com critérios definidos para observar ou se tratou de um julgamento sem definição operacional de critérios de avaliação? Essas são perguntas que se fazem presentes, pois sem a definição clara dos critérios de julgamento, não é possível interpretar quais características compõem o fator em questão e novamente a credibilidade em termos de interpretação dos dados do PMK volta à baila. Se esse dado é de importância, cabe perguntar por que a autora do Manual justificou as baixas correlações com outros instrumentos que medem personalidade em razão dos distintos fundamentos teóricos dos diferentes testes. De fato, eles podem ser distintos, mas estão operacionalizados e disponíveis para análise e interpretação.

Ao lado disso, deve-se agora ressaltar que o Manual não é claro no que se refere à definição de cada um dos fatores. Esse fato dificulta um pouco mais a compreensão desses achados e da posição da autora do Manual.

A interpretação dada ao estudo de Takala (1953) também merece comentários. Dos 34 coeficientes, três deles foram inferiores a 0,20 , que podem ser considerados nulos; sete outros estiveram entre 0,21 a 0,40, classificáveis como fracos; e 24 ficaram entre 0,41 e 0,60 , considerados bons. A interpretação apresentada no Manual foi que as variáveis (subtestes) "revelaram uma correlação bastante elevada no conjunto." (p. 194), o que é no mínimo questionável (Guilford, 1936; Nunnally, 1967; Anastasi, 1988; Aiken, 1997). Desnecessário comentar que não é apresentada a fonte que possibilitou esse tipo de julgamento qualitativo dos coeficientes de correlação.

Cita também que o autor não encontrou diferenças significativas entre a mão direita e esquerda. Ao lado disso, foi comentado que a análise fatorial resultou em três fatores e justificou-se que esse resultado é coerente, pois as "personalidades coerentes, tanto nas bem estruturadas como em personalidades patológicas" tenderiam a apresentar correlações altas (não houve nenhuma); "as correlações baixas, nos casos fortemente incoerentes, e correlações medianas nos outros casos" (p. 194).

Essa interpretação oferecida no Manual é no mínimo estranha, pois fica muito difícil entender como se chegou a essas conclusões com base nos resultados de uma análise fatorial (Gorsuch, 1983; Morrison, 1990). De fato, o que esse resultado estaria indicando é que não se sustentou a hipótese de que as mãos direita 
e esquerda forneceriam informações diferentes (uma endógena e a outras circunstancial), nem que as seis medidas (tônus vital, agressividade, reação vivencial, emotividade, dimensão tensional e predomínio tensional) se diferenciaram no grupo estudado. Ao mesmo tempo, a interpretação dos três fatores apresentada no Manual não se refere tampouco às três grandes constelações da personalidade (normais, limítrofes e patológicas). $\mathrm{Na}$ realidade, não se consegue saber a que a autora do Manual está se referindo, nem o que possibilitou sua inferência, principalmente quando se busca uma relação com os fundamentos teóricos do PMK e a estrutura de análise da personalidade propostos. Esses fatos colocam sérias dúvidas na interpretabilidade do PMK, tal como recomendada.

Nesse mesmo contexto, há que se considerar o estudo de Rennes (1965). Novamente, valendo-se da análise fatorial, tampouco sustentou os seis fatores e, menos ainda, as três grandes constelações da personalidade. Também é colocada em dúvida a teoria miocinética, que se refere à mão direita e esquerda, pois não foram encontradas diferenças entre elas.

No Manual, os resultados dessa pesquisa foram considerados "negativos" e "confusos", e colocam como justificativa que o resultado é conflitante com o sistema interpretativo proposto por Mira y Lopez. Tudo leva a crer que as suposições interpretativas do PMK não se confirmaram, pois a maneira como as medidas se configuraram foram muito diferentes do preconizado. Aparentemente, os resultados não foram nem confusos nem negativos, apenas dados de realidade, ou seja, o psiquismo das pessoas pesquisadas não ofereceu suporte às suposições interpretativas de Mira y Lopez (Gorsuch, 1983; Morrison, 1990), tal como foram elaboradas.

Como resultado parecido a esse (no que se refere a encontrar estruturas fatoriais que não sustentam a estrutura teórica do PMK) já fora relatado, tudo parece indicar, que a interpretabilidade do PMK não se sustentaria quando se procura evidência de validade em relação à estrutura interna dos itens. $\mathrm{Na}$ realidade, os resultados não amparam a configuração preconizada no que concerne à relação das medidas e do funcionamento psíquico das pessoas analisadas. Em decorrência, quando se pensa que a autora do Manual desacredita medidas de correlação com outros testes, por estarem embasados em teorias distintas, quando se observa que os estudos sobre a estrutura interna não fornece evidência para a proposta do teste e que as investigações que levam em conta grupos-critério sofrem de sérias restrições metodológicas, estabelecem-se consistentes dúvidas sobre a interpretabilidade desse instrumento.
Em relação aos índices de correlação oferecidos pelo Manual na página 198, alguns detalhes merecem destaque. Em primeiro lugar, não é apresentada qualquer indicação de quem realizou a pesquisa ou se ela foi publicada, ou quando foi realizada (nas páginas anteriores, mesmo que não publicada, era fornecido quem havia feito e a data). Da forma com que foi apresentada, as pessoas estão impossibilitadas de obter qualquer informação sobre esses dados. A questão que se coloca é se os psicólogos são obrigados a acreditar em dados com essas características. Ao mesmo tempo, fica a questão concernente a como referir o resultado de uma pesquisa científica: deve ser relatado de acordo com os procedimentos usuais do relato científico ou cada pessoa pode fazer um relato segundo suas idiossincrasias e crenças?

A afirmação de que esses dados auxiliarão "os usuários do teste na interpretação da sua validade" (p. 198) de maneira "mais eficiente" entra em contradição com o fato de assumirem que se trabalhará com o valor de 0,50 como aceitável, apesar de antes haver afirmado que o valor de 0,71 seria suficiente para que a validade da medida fosse satisfatória. Mas o fato de variar o critério de avaliação parece que não foi observado ou não foi considerado como contraditório, pois não há qualquer citação para que sejam propostos tais valores ou para justificar essa mudança de critério. $\mathrm{E}$, na realidade, há uma grande diferença qualitativa entre esses valores (Guilford, 1936; Nunnally, 1967; Nunnally, 1972; Cronbach, 1983; Anastasi, 1988; Aiken, 1997; Arias, 1996).

Nas seis colunas do Quadro, fatos muito interessantes também puderam ser constatados. As correlações entre mão direita e esquerda, como também PMK e inteligência, foram denominadas de validade simultânea (fonte 16 e 18). Mas também correlações entre mão direita e esquerda foram denominadas de reteste (fonte 25) e validade concorrente (fonte 52). Esses dados parecem sugerir que os termos psicométricos (validade simultânea, validade concorrente e reteste) foram usados sem um critério ou definição psicométrica. Nesse mesmo contexto, o método "com correção de atenuação" não é definido e parece não se incluir entre os procedimentos para evidências de validade, nem tampouco nos de precisão. Maiores detalhes para se observar essa imprecisão e confusão terminológica há em literatura bastante grande a respeito (dentre muitos, pode-se consultar Guilford, 1936; Nunnally, 1967; Nunnally, 1972; Cronbach, 1983; Anastasi, 1988; Aiken, 1997; Arias, 1996).

O fato básico de toda essa confusão terminológica confronta o objetivo do Quadro, que 
serviria para mostrar "alguns índices de correlação que, de forma mais eficiente, podem ajudar os usuários do teste na interpretação da sua validade" (p. 198). Qual a interpretabilidade possível ante esse tipo de informação?

Ao lado disso, independentemente dessas incorreções e incongruências, ao se analisar as correlações fornecidas (índices entre 0,52 a 0,95) parecem muito nítidas pelo menos duas coisas. Uma delas é que as medidas do PMK seriam fatoráveis. Outra, que as medidas das mãos direita e esquerda parecem indicar a presença de uma comunalidade maior do que a devida, pelo fato de se defender que se trata de medidas constitucionais e fenotípicas, o que traria consigo a expectativa de coeficientes de correlação bem mais baixos. Ao mesmo tempo, os estudos fatoriais relatados parecem ter fornecido indicações de que a estrutura interpretativa proposta pela PMK não se sustentaria, e que há sérias dúvidas em relação às informações das mãos direita e esquerda poderem ser interpretadas como consituticionais (genotípicas) ou construídas (fenotípicas).

Finalmente, resta comentar que no capítulo relativo aos estudos de validade não se encontraram pesquisas que levassem em consideração a variedade de quadros, psicopatológicos, próximos a, e de outras naturezas que são tratadas no capítulo 11. Mesmo comentário pode ser feito em relação às grandes constelações da personalidade, cujo único estudo que poderia se aproximar de algo dessa natureza deixa a desejar, porque não há representantes de todas as três constelações e manifestações particulares de cada uma.

\section{Algumas considerações finais}

O Manual apresenta uma série de descuidos, alguns deles já comentados anteriormente, pois se tratava de dados de validade. Nada obstante, há outros tipos de equívocos que vale a pena comentar, pois interferem também na interpretabilidade do PMK.

A primeira observação interessante é que, se na página 19 é informado que a apresentação oficial de Mira y Lopez na Academia Real de Medicina de Londres foi em 10 de outubro de 1939, na página 190 do mesmo Manual é relatado que essa apresentação foi em 1940, quando "expôs as suas conclusões, cujos resultados preliminares podem ser considerados, sem dúvida, como uma tentativa de validade do teste". Exposto dessa forma, pela autora do Manual, pode-se considerar que a informação relatada na Academia de Londres não foi suficiente para justificar a interpretabilidade dos dados apresentados.
No Manual são apresentados vários autores para mostrar os princípios psicológicos nos quais foi fundamentado o PMK e, talvez, o pensamento de Ribot (1914), quando afirmou que a organização motora seria a base da vida psíquica e o "esqueleto do inconsciente", seja um dos melhores representantes dos autores citados, pelo fato de que essa literatura esteve à mão de Mira y Lopes. Também é citada a obra de Wallon, que na época (antes de 1939) não tinha publicações a esse respeito e o livro citado data de 1942. Com base nessa incoerência, e outras que podem ser observadas no texto, é possível interpretar que a Teoria Motriz da Consciência, tal como descrita, valendo-se dos autores comentados, não foi a que fundamentou a construção do PMK, pois boa parte dela foi escrita depois de sua criação.

Mas há também citação de estudos considerados não-concluídos e não-publicados. A esse respeito pode-se citar, a título de exemplo, dois casos. Um deles, é o possível estudo de Bauzer e Martins (1950), afirmando que se têm notícias de que se encontraram mais de cem correlações, e seria uma possível análise fatorial não concluída; o outro, de Ombredanne, Ancelin Schutzenberger e Faverge (1949), que seria uma nota preliminar sobre estudo de fidedignidade. $\mathrm{O}$ que se pode fazer e como interpretar esse tipo de informação?

Mas o mais chamativo é aquele que foi escolhido para ter o maior espaço dedicado a relatar pesquisas, que foi o referente ao estudo de Martins (1971), de cinco páginas e não publicado, segundo as informações do Manual. Esse estudo relataria dados de "fidedignidade e precisão" (p. 196) com 100 adultos, por meio de três aplicações do PMK. As correlações entre as aplicações variaram entre 0,45 e 0,66 . Ao lado disso, no Manual são mostradas também correlações (média das pontuações das três aplicações) entre os conjuntos teóricos dos traçados (extra e intratensão, agressividade, depressão, emotividade, excitaçãoinibição e impulsividade), informando que variaram entre 0,90 e 0,95 . Aparentemente, foram intercorrelações entre as medidas de cada conjunto teórico, pois a seguir é informado, que ao se considerarem as intercorrelações entre os elementos de cada conjunto, elas foram mais baixas, ficando num possível intervalo de 0,11 a 0,92 . O Manual apresenta o que denominou de Quadro 12.2, no qual fornece "intercorrelações médias, intercorrelações das variáveis e correlação estatística", o que ajuda bastante a obscurecer o significado das informações, principalmente do que seja uma "correlação estatística".

Mas há estudos citados nas referências, com muitas indicações de serem estudos psicométricos, que 
não são mencionados nesse capítulo. Ao mesmo tempo, o problema do critério de escolha do que informar e não informar ao leitor do Manual não é esclarecido.

Diante do exposto, fica a dúvida sobre o critério usado pelo Conselho Federal de Psicologia para avaliar que o PMK possui alguma evidência de validade brasileira, conseguida nos últimos anos. $\mathrm{Ou}$ algum estudo brasileiro ou estrangeiro.

\section{Referências}

Aiken, L. R. (1997). Psychological testing and assessment (9 ed.). Boston: Allyn and Bacon.

Anastasi, A. (1988). Psychological Testing (6 ${ }^{\mathrm{a}}$ ed.). Nova Iorque: Macmillan.

Arias, R. M. (1996). Psicometria: teoría de los tests psicológicos y educativos. Madrid: Sintesis.

Campos, D. M. (1999). O teste do desenho como instrumento de diagnóstico da personalidade: validade, técnica de aplicação e normas de interpretação. $31^{\mathrm{a}}$ ed. PetrópolisRJ: Vozes.

Cronbach, L. J. (1983). Fundamentals of psychological testing. Nova Iorque: Harper.

Goodenough, F. L. (1926). Measurement of intelligence by drawings. Nova Iorque: World Book Company, The House of Applied Knowledge.

Sobre o autor:

Fermino Fernandes Sisto é professor titular aposentado pela UNICAMP e professor do Programa de PósGraduação Stricto Sensu em Psicologia da Universidade São Francisco.
Gorsuch, R. L. (1983). Factor analysis. Hillsdale, NJ: Erlbaum.

Guilford, J. P. (1936). Psychometric methods. Londres: McGraw-Hill.

Mira, A. M. G. (2004). PMK: psicodiagnóstico miocinético. manual. São Paulo: Vetor.

Morrison, D. F. (1990). Multivariate statistical methods. Nova Iorque: McGraw-Hill.

Nunnally, J. C. (1967). Psychometric theory. Nova Iorque: McGraw-Hill.

Nunnally, J. C. Jr. (1972). Introduction to psychological measurement. Nova Iorque: McGraw-Hill.

Ribot, T. (1914). La vie inconsciente et les mouvements. Paris: Librarie Félix Alcan. Leitura online http://openlibrary.org/b/OL14018331M/vie_inc onsciente_et_les_mouvements.

Takala, M. (1953). Studies of psychomotor personality tests. Annales Academiae Scientiarum Fennicae, Helsinki, 3, 67-130.

Recebido em fevereiro de 2010 Reformulado em maio de 2010 Aprovado em junho de 2010 